\title{
Viral infection related venous thromboembolism: potential mechanism and therapeutic targets
}

\author{
Yunan Yu ${ }^{1 \#}$, Yuqin Shen ${ }^{1 \#}, \mathrm{Jie} \mathrm{Li}^{1}$, Jie Liu ${ }^{2}$, Shangfeng Liu ${ }^{3}$, Haoming Song ${ }^{1}$ \\ ${ }^{1}$ Department of Cardiology, Tongji Hospital of Tongji University, Shanghai 200065, China; ${ }^{2}$ Translational Center for Stem Cell Research, Tongji \\ Hospital, Stem Cell Research Center, Tongji University School of Medicine, Shanghai 200065, China; ${ }^{3}$ Oral Biomedical Engineering Laboratory, \\ Shanghai Stomatological Hospital, Fudan University, Shanghai 200001, China \\ Contributions: (I) Conception and design: Y Yu, Y Shen, S Liu, H Song; (II) Administrative support: HS; (III) Provision of study materials or patients: \\ All authors; (IV) Collection and assembly of data: All authors; (V) Data analysis and interpretation: Y Yu, Y Shen; (VI) Manuscript writing: All \\ authors; (VII) Final approval of manuscript: All authors. \\ \#These authors equally contributed to this work. \\ Correspondence to: Haoming Song, PhD. Department of Cardiology, Tongji Hospital of Tongji University, 389 Xincun Road, Shanghai 200065 , \\ China. Email: songhao-ming@163.com; Shangfeng Liu, PhD. Oral Biomedical Engineering Laboratory, Shanghai Stomatological Hospital, Fudan \\ University, 356 Beijing Road, Shanghai 200001, China. Email: shangfeng_liu683@fudan.edu.cn.
}

\begin{abstract}
With the development and improvement of new techniques in cell biology, molecular biology and biostatistics, increasing studies have been conducted to investigate the mechanism of venous thromboembolism (VTE). Some studies have found that the pathogenesis of VTE is largely related to the abnormality of the immune system as demonstrated by the thrombosis in mice infected with H1N1 influenza and the changes in the expression of genes related to immune system. According to the protein-protein interaction analysis of the differential expression of the immune system in VTE patients, the presence of venous thrombosis was related to the abnormal expression of molecules in JAK/STAT signaling pathway. We discussed the mechanism of VTE and provided two novel therapeutic targets for venous thrombosis: AKT1 and AOX1. Our review may be helpful for better understanding of the current research status of VTE, and provide evidence on the molecular mechanism of VTE.
\end{abstract}

Keywords: Venous thromboembolism (VTE); viral infection; JAK/STAT signaling pathway

Submitted Sep 19, 2019. Accepted for publication Feb 11, 2020.

doi: 10.21037/apm.2020.04.05

View this article at: http://dx.doi.org/10.21037/apm.2020.04.05

\section{Introduction}

Venous thromboembolism (VTE) refers to both general terms for pulmonary thromboembolism (PTE) and deep venous thrombosis (DVT). VTE is a common cardiovascular disease and is mainly found in patients with hypercoagulative blood and elevated thrombin expression which may cause platelet adhesion and aggregation or deposition in the intima of blood vessels, resulting in impaired vascular functions. In addition, complicated interactions between endothelial cells, platelets and tissue cells have been found to be involved in the pathogenesis of VTE.

\section{Research status of VTE}

Due to high rates of misdiagnosis, morbidity and mortality, VTE has become one of the most important medical issues worldwide (1,2). In the United States, nearly 900,000 new PTE patients are diagnosed each year and PTE has been the third leading cause of death $(3,4)$, only second to malignant tumors and myocardial infarction.

The homeostasis in human body is maintained by complex mechanisms, such as the neuromodulation and humoral regulation. Any abnormality in certain parts of the body may lead to the presence of diseases. The studies of biological reactions that cause thrombosis are gradually 
revealing the veil of VTE.

The classic Virchow triad has involvement of three main elements: stasis, hypercoagulability, and endothelial dysfunction. However, the three elements theory cannot explain the clinical confusion of VTE. Many studies have shown that aging, postoperative long term immobilization, trauma, tumor, virus infection and other risk factors can promote the occurrence of venous thrombosis $(5,6)$. According to a recent hypothesis, by evaluating patients with VTE and studying the local predisposition and other risk factors for VTE formation, it is shown that VTE is caused by a combination of factors (7). The genetic factors related to the pathogenesis of VTE mainly include: antithrombin III (ATIII) factor deficiency, protein C and protein $\mathrm{S}$ deficiency, $\mathrm{V}$ Leiden mutation, prothrombin 20210 gene mutation, congenital fibrinogen gene mutation and other factors (8).

Although the present theory on thrombosis cannot fully explain the pathogenesis of VTE, it provides a direction and research basis for us to study the pathogenesis of VTE.

\section{Role of viral infection in VTE}

Thrombosis is a multistep process that is influenced by a variety of genetic and environmental factors. We have known that viral infection related VTE is caused by the collapse of the balance function of systemic immune cells, which lacks the function of effectively clearing the malignant tumor cells or infected venous cells, and the venous cells infected with virus cause infectious inflammation in veins.

The inflammation causing thrombosis can be divided into infectious inflammation and non-infectious inflammation. Viral infection is the infectious inflammation, which has different effects on the formation of thrombi.

Preliminary progression has been achieved about the effect of viral infection on VTE. VTE has been reported in patients with influenza virus, human immunodeficiency virus (HIV), cytomegalovirus, herpes simplex virus and other viral infections (9-11). Liu et al. (12) found mice infected with different strains of $\mathrm{H} 1 \mathrm{~N} 1$ and $\mathrm{H} 3 \mathrm{~N} 2$ virus developed pathological changes in the lung and thrombosis in several lung tissues.

In a case-control study conducted between 2003 and 2007 in French, investigators studied whether influenza vaccination reduced the risk of VTE, and their results showed that influenza vaccination was able to reduce the risk of cardiovascular events in patients with coronary heart disease, but its effect on the risk of VTE has not yet been explored (13). HIV is an RNA lentivirus that can cause the human immunodeficiency syndrome. In HIV infected patients, combination antiretroviral therapy was found to significantly improve the survival rate, but caused a variety of metabolic complications, including thromboembolism (9). The mechanism underlying the cytomegalovirus induced coagulation has not been elucidated. Although these mechanisms are incomplete, we speculate that cytomegalovirus infection may be regarded as a risk factor for thrombosis according to our clinical experience (14). Liu $e t$ al. detected the viral load in lung tissues of mice after infection and examine the pathological changes in lung tissues. In this study, mice were infected with $\mathrm{H} 1 \mathrm{~N} 1$ and $\mathrm{H} 3 \mathrm{~N} 2$ viruses, and all the mice developed interstitial pneumonia of different degrees as demonstrated by pathological examinations. Thrombosis (mainly composed of fibrins and platelets) was noted in multiple small vessels of lung tissues in $13 \mathrm{H} 1 \mathrm{~N} 1$ infected mice and $6 \mathrm{H} 3 \mathrm{~N} 2$ infected mice. This suggested that $\mathrm{H} 1 \mathrm{~N} 1$ and $\mathrm{H} 3 \mathrm{~N} 2$ influenza virus infection may cause thrombosis in the lung (12).

By comparing the characteristics of inflammatory responses in vivo caused by various viruses with the body functions of patients with VTE, it is not difficult to find that the viral infection has an impact on the formation of VTE, and the molecular mechanism of viral infection on VTE remains to be further studied. At the same time, VTE is not only influenced by the living environment, but also by the genotype. Thus, genes related to signaling pathways involved in the pathogenesis of VTE are also targets in future studies. The following section introduces the molecular mechanism underlying the VTE formation after virus infections.

\section{Molecular mechanism underlying the viral infection related VTE}

Studies have compared the genomics and cellular immune functions between clinical symptomatic VTE patients and healthy controls (15-18). Results showed that the mRNA expression of cytokines related to VTE reduced significantly in patients with VTE. In VTE patients, cytological examination showed the function of NK cells decreased significantly, the $\mathrm{T}$ cell antigen recognition and killing function were significantly compromised, genomics 
and cytological examination consistently showed that the formation of symptomatic VTE was closely related to the immune dysfunction (19-21).

The development of biology and molecular cell biological technology has provided the possibility of studying the pathogenesis of thrombosis. In a study, 289 patients were divided into the control group, infection group, VTE group and VTE + infection group. Results showed $\mathrm{CD}^{+}, \mathrm{CD}^{+}$and $\mathrm{CD}^{+}{ }^{+} \mathrm{T}$ lymphocytes significantly reduced in the infection group, and the $\mathrm{CD} 4^{+} / \mathrm{CD} 8^{+}$ ratio markedly increased $(\mathrm{P}<0.05) . \mathrm{CD}^{+}$and $\mathrm{CD} 8^{+} \mathrm{T}$ lymphocytes dramatically reduced in the VTE + infection group and VTE group, and the $\mathrm{CD} 4^{+} / \mathrm{CD}^{+}$ratio markedly increased $(\mathrm{P}<0.05)$. In the infection group, VTE group and VTE + infection group, the proportion of $\mathrm{CD}^{+}$and $\mathrm{CD} 8^{+} \mathrm{T}$ lymphocytes decreased, and that of $\mathrm{CD} 4^{+} / \mathrm{CD} 8^{+}$ increased. These findings suggest that infected patients with VTE have immune dysfunction, while VTE patients often have concomitant infection. Moreover, the ability of $\mathrm{T}$ lymphocytes to directly kill virus decreased significantly, suggesting the inflammatory mechanism underlying the occurrence and development of VTE (19). In order to systematically compare the genomics and cellular immunity between clinical symptomatic VTE patients and controls, the immunological pathogenesis of VTE was discussed. Microarray assay has shown significant down-regulated mRNA expression of genes related to non-specific cellular immunity and cytokines. Abnormal expression of $\mathrm{CD}^{+}$, $\mathrm{CD}^{+}, \mathrm{CD}^{+}, \mathrm{NK}$ marker $\mathrm{CD} 16^{+} 56^{+}, \mathrm{CD} 19^{+}, \mathrm{CD}^{+} / \mathrm{CD}^{+}$ ratio was detected in 54 of 56 patients. In patients with VTE, microarray assay revealed an imbalance in the mRNA expression of genes associated with the immune system. The mRNA expression of genes associated with non-specific immune cells and cytokines was significantly up-regulated, and that of genes related to cellular immunity markedly down-regulated. In VTE patients, cytological examination showed that the function of NK cells was significantly compromised, and the antigen recognition and killing activity of $\mathrm{T}$ cells decreased dramatically. The consistency between genomic and cytological examinations indicated that the pathogenesis of symptomatic VTE was closely related to infections and the immune dysfunction (19). A recent study shows the difference of gene expression after infection, and the gene expression associated signaling pathways was further investigated (22).

Current biological researches and the development of molecular cell biology technology have provided us with a lot of possibilities for studying the causes of thrombosis, such as enzyme linked immunosorbent assay (ELISA), magnetic resonance imaging (MRI) and differential gene expression analysis.

Because of the high catalytic efficiency of the enzyme in ELISA, the reaction effect can be greatly amplified, which makes the determination method reach a high sensitivity. Therefore, ELISA detection is widely used in cardiovascular diseases (23).

MRI scanning was performed in the aorta, risk factors were collected, and the carotid and femoral ultrasound was performed. The aortic elasticity was compared among 19 patients with familial hypercholesterolemia $(\mathrm{FH}), 18$ with type 2 diabetes mellitus (DM) and 30 controls. Results showed that the arterial elasticity was significantly different between FH patients and DM patients (24). This is an important method of direct case diagnosis in addition to pathological observation.

Many studies have reported multiple viral infections in case of VTE. Mice infected with the virus were found to develop thrombosis in the small blood vessels of lung, and clinical and animal studies also reveal the increased risk for VTE following viral infection. This research found that the virus infection before the project team may affect the expression of genes related to immune system, leading to the thrombosis (25).

\section{FAK/STAT signaling pathway and VTE}

Recently, we used H1N1 flu virus infected immunodeficiency mice model, combined with the second generation of the transcriptome sequencing and multiple ELISA technology, detected the changes of related signaling pathways, to study the effect of virus infection on the pathogenesis of VTE. Our results showed JAK/STAT signaling pathway was involved in the pathogenesis of VTE patients. These findings were further investigated in human umbilical vein endothelial cells in vitro. Results confirmed the close relationship between JAK/STAT signaling pathway and VTE, Protein - protein interaction networks of the differentially expressed genes (DEGs) in VTE (Figure 1).

The JAK/STAT signaling pathway can be activated by some cytokines, and involved in many important biological processes such as cell proliferation, differentiation, apoptosis, and immune regulation (26-28).

JAK/STAT signaling pathway consists of three components, tyrosine kinase related receptors, tyrosine 


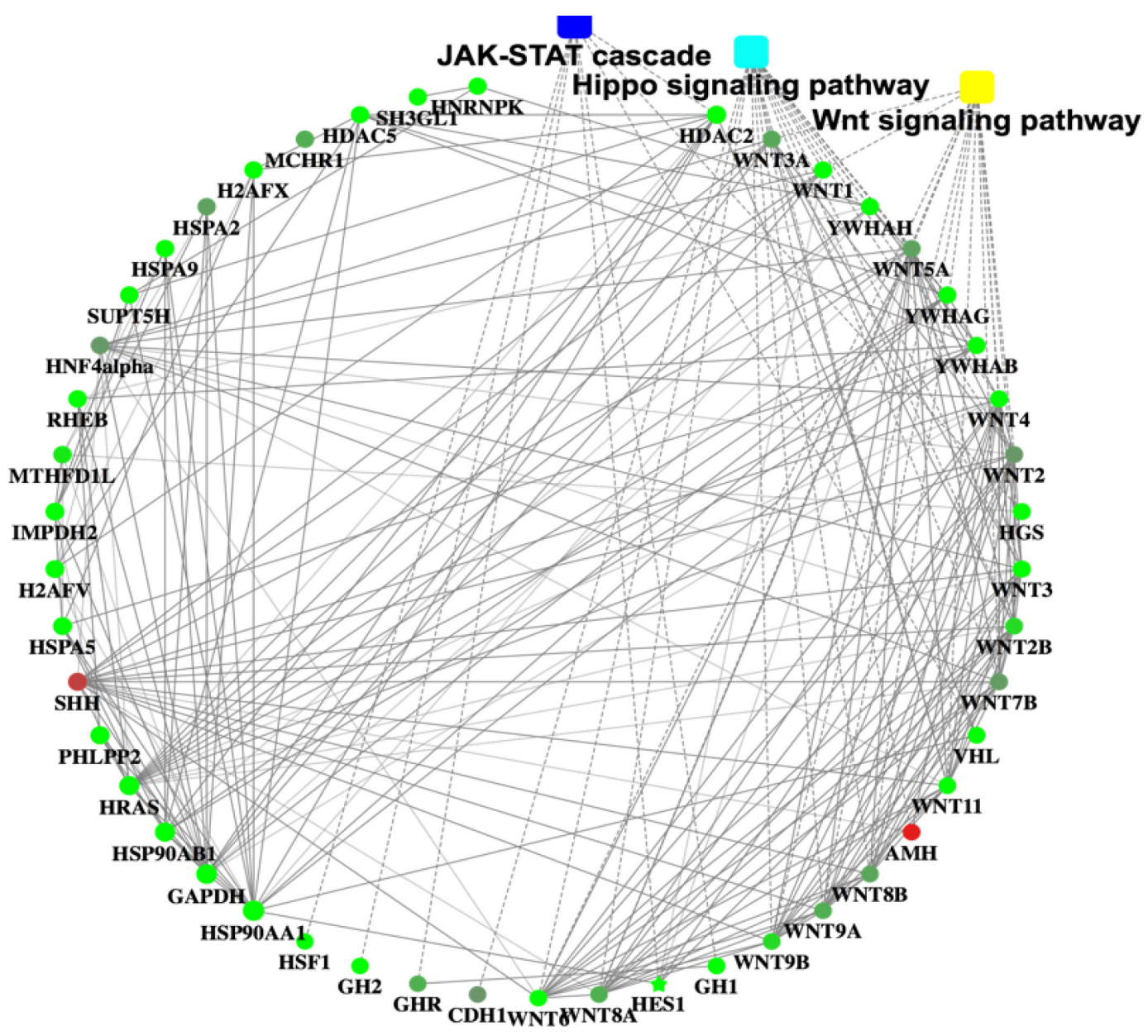

Figure 1 Protein-protein interaction networks of the differentially expressed genes (DEGs) in VTE. VTE, venous thromboembolism.

kinase JAK and transcription factor STAT (Figure 2).

To date, four members have been identified in the JAK protein family: JAK1, JAK2, JAK3 and Tyk2. They have 7 JAK structurally homologous structure domains (JAK homology domain, $\mathrm{JH}$ ), including $\mathrm{JH} 1$ structure domain for kinase domain area, JH2 structure as "false" kinase area, and JH6 and JH7 as the receptor area (29-32).

In recent years, studies have been conducted to investigate the role of JAK/STAT signaling pathway in the pathogenesis of various diseases. There is evidence showing that the mutation of genes related to JAK/STAT signaling pathway and abnormal signaling transduction of JAK/STAT pathway are related to the pathogenesis of some diseases. The $7 A K 3$ and $T Y K 2$ genes are responsible for the survival of mice by regulating the immune system of immunodeficient mice $(33,34)$.

\section{Prospect of the study on VTE}

Our understanding of VTE has changed dramatically over the past few decades, from simple laboratory tests and early clinical observations of patients with rare genetic diseases to the introduction of genetic recombination techniques, genome-wide association study and second-generation sequencing technologies and concepts. Studies on the coagulation and anti-coagulation systems are of great importance to understand the pathophysiology of VTE. On the basis of findings from clinical studies, we are able to develop new treatments for VTE and new strategies for the prevention of VTE in high-risk subjects.

VTE is not only a cardiovascular disease, but also closely related to viral infections. The effect of viral infection on VTE is likely to be mediated by the immune system. Even though there are some immune-related 


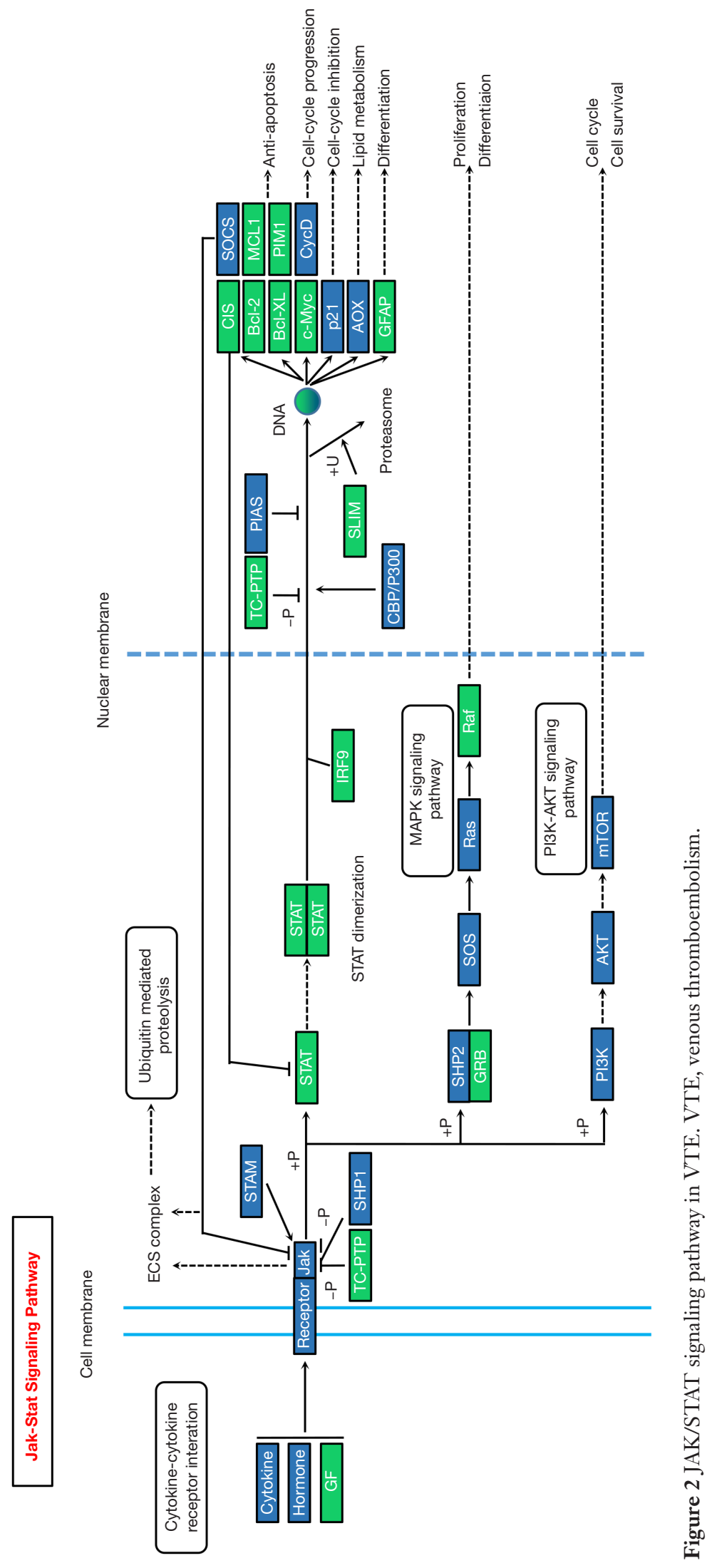


therapies suggested in VTE, they mainly focus on antiinflammatory interventions and remain controversial. The specific molecular mechanism underlying the viral infection related VTE remains unknown. Although some studies have investigated the signaling pathways related to the pathogenesis of VTE and our recent study showed that JAK/STAT pathway might play an important role in VTE, and more clinical and basic studies are needed to confirm these findings. Further researches should focus on the whole immune system in a cellular lever and find out how they operate systematically and interact with different types of cells in VTE.

\section{Acknowledgments}

Funding: None.

\section{Footnote}

Conflicts of Interest: All authors have completed the ICMJE uniform disclosure form (http://dx.doi.org/10.21037/ apm.2020.04.05). The authors have no conflicts of interest to declare.

Ethical Statement: The authors are accountable for all aspects of the work in ensuring that questions related to the accuracy or integrity of any part of the work are appropriately investigated and resolved.

Open Access Statement: This is an Open Access article distributed in accordance with the Creative Commons Attribution-NonCommercial-NoDerivs 4.0 International License (CC BY-NC-ND 4.0), which permits the noncommercial replication and distribution of the article with the strict proviso that no changes or edits are made and the original work is properly cited (including links to both the formal publication through the relevant DOI and the license). See: https://creativecommons.org/licenses/by-nc-nd/4.0/.

\section{References}

1. Ro A, Kageyama N, Tanifuji T, et al. Pulmonary thromboembolism: overview and update from medicolegal aspects. Leg Med (Tokyo) 2008;10:57-71.

2. Weinmann EE, Salzman EW. Deep-vein thrombosis. N Engl J Med 1994;331:1630-41.

3. Fowkes FJ, Price JF, Fowkes FG. Incidence of diagnosed deep vein thrombosis in the general population: systematic review. Eur J Vasc Endovasc Surg 2003;25:1-5.

4. Smeeth L, Cook C, Thomas S, et al. Risk of deep vein thrombosis and pulmonary embolism after acute infection in a community setting. Lancet 2006;367:1075-9.

5. Kostadima E, Zakynthinos E. Pulmonary embolism: pathophysiology, diagnosis, treatment. Hellenic J Cardiol 2007;48:94-107.

6. Kyrle PA, Eichinger S. Deep vein thrombosis. Lancet 2005;365:1163-74.

7. Denninger MH, Chait Y, Casadevall N, et al. Cause of portal or hepatic venous thrombosis in adults: the role of multiple concurrent factors. Hepatology 2000;31:587-91.

8. Zang F, Zhao Y, Wu F. Genetic susceptibility and genetic screening to venous thromboembolism. International Journal of Internal Medicine 2007;34:673-5, F3.

9. Abgueguen P, Delbos V, Ducancelle A, et al. Venous thrombosis in immunocompetent patients with acute cytomegalovirus infection: a complication that may be underestimated. Clin Microbiol Infect 2010;16:851-4.

10. Görek A, Akçay S, Ibiş O, et al. Herpes simplex virus infection, massive pulmonary thromboembolism and right atrial thrombi in a single patient: Case report. Heart \& Lung 2007;36:148-53.

11. Matta F, Yaekoub AY, Stein PD. Human immunodeficiency virus infection and risk of venous thromboembolism. Am J Med Sci 2008;336:402-6.

12. Liu Y, Xu Y, Deng W, et al. Microvascular Thrombosis in the Lung of Different Strains of Mice Infected with Influenza A Virus. Chinese Journal of Comparative Medicine 2012;22:1-5.

13. Zhu T, Carcaillon L, Martinez I, et al. Association of influenza vaccination with reduced risk of venous thromboembolism. Thromb Haemost 2009;102:1259-64.

14. Fridlender ZG, Khamaisi M, Leitersdorf E. Association between cytomegalovirus infection and venous thromboembolism. Am J Med Sci 2007;334:111-4.

15. Cohen AT, Tapson VF, Bergmann JF, et al. Venous thromboembolism risk and prophylaxis in the acute hospital care setting (ENDORSE study): a multinational cross-sectional study. Lancet 2008;371:387-94.

16. Rosendaal FR. Venous thrombosis: a multicausal disease. Lancet 1999;353:1167-73.

17. Sproul EE. Carcinoma and venous thrombosis: the frequency of association of carcinoma in the body or tail of the pancreas with multiple venous thrombosis. The American Journal of Cancer 1938;34:566-85.

18. Vandenbroucke JP, Rosing J, Bloemenkamp KW, et al. Oral contraceptives and the risk of venous thrombosis. N 
Engl J Med 2001;344:1527-35.

19. Duan Q, Gong Z, Song H, et al. Symptomatic venous thromboembolism is a disease related to infection and immune dysfunction. Int J Med Sci 2012;9:453-61.

20. Lv W, Wang L, Duan Q, et al. Characteristics of the complement system gene expression deficiency in patients with symptomatic pulmonary embolism. Thromb Res 2013;132:e54-7.

21. Zhou L, Song H, Xu W, et al. Immune function of peripheral $\mathrm{T}$ cells in patients with venous thromboembolism or coronary artery atherosclerosis. Rev Port Cardiol 2014;33:339-44.

22. Yang J, Cai W, Lu X, et al. RNA-Sequencing Analyses Demonstrate the Involvement of Canonical Transient Receptor Potential Channels in Rat Tooth Germ Development. Front Physiol 2017;8:455.

23. Yan W, Song H, Jiang J, et al. Characteristics of B cell associated gene expression in patients with coronary artery disease. Mol Med Rep 2016;13:4113-21.

24. Soljanlahti S, Autti T, Hyttinen L, et al. Compliance of the aorta in two diseases affecting vascular elasticity, familial hypercholesterolemia and diabetes: a MRI study. Vasc Health Risk Manag 2008;4:1103-9.

25. Bausek N. JAK-STAT signaling in stem cells and their niches in Drosophila. JAKSTAT 2013;2:e25686.

26. Esmon CT. Basic mechanisms and pathogenesis of venous thrombosis. Blood Rev 2009;23:225-9.

Cite this article as: Yu Y, Shen Y, Li J, Liu J, Liu S, Song H. Viral infection related venous thromboembolism: potential mechanism and therapeutic targets. Ann Palliat Med 2020;9(3):1257-1263. doi: 10.21037/apm.2020.04.05
27. Gu Y. A preliminary study on the differential expression of genes in peripheral blood individual nuclear cells in patients with pulmonary thromboembolism. Cardiopulmonary Vascular Disease Journal 2005;24:177.

28. Haoming S, Lemin W, Zhu G, et al. T cell-mediated immune deficiency or compromise in patients with CTEPH. Am J Respir Crit Care Med 2011;183:417-8.

29. Cai B, Cai JP, Luo YL, et al. The Specific Roles of JAK/STAT Signaling Pathway in Sepsis. Inflammation 2015;38:1599-608.

30. Coskun M, Salem M, Pedersen J, et al. Involvement of JAK/STAT signaling in the pathogenesis of inflammatory bowel disease. Pharmacol Res 2013;76:1-8.

31. Villarino AV, Kanno Y, Ferdinand JR, et al. Mechanisms of $\mathrm{Jak} / \mathrm{STAT}$ signaling in immunity and disease. J Immunol 2015;194:21-7.

32. Yan W, Song $Y$, Zhou L, et al. Immune Cell Repertoire and Their Mediators in Patients with Acute Myocardial Infarction or Stable Angina Pectoris. Int J Med Sci 2017;14:181-90.

33. Karaghiosoff M, Neubauer H, Lassnig C, et al. Partial impairment of cytokine responses in Tyk2-deficient mice. Immunity 2000;13:549-60.

34. Thomis DC, Gurniak CB, Tivol E, et al. Defects in B lymphocyte maturation and $\mathrm{T}$ lymphocyte activation in mice lacking Jak3. Science 1995;270:794-7. 